\title{
Ulrich Teichler. Sistemas comparados de educación superior en Europa. VI Congreso CIDUI. 2010. 359 páginas. ISBN 978-84-9921- 002-5.
}

Desde el año 2010 hemos visto implantado tanto en España como en otros países europeos el conocido como "Plan de Bolonia". Actualmente, no son pocas las voces que discrepan sobre los resultados obtenidos. Pero, debemos también conocer qué es lo que predominaba en Europa anteriormente en materia de educación superior (sistemas de acceso y programas de estudio diferentes, falta de movilidad estudiantil y laboral...). Pues bien, este libro nos proporciona esa posibilidad ya que el ámbito temporal en que se centra el autor va desde los años sesenta hasta el año 2006.

Cuando se me brindó la oportunidad de realizar la recensión de este libro, no sabía el grado de interés que iba a despertar en mí. A pesar de que, en este sentido, debo reconocer que al principio pensé que muy posiblemente se tratarían aspectos no actuales o de poco interés respecto a nuestro actual sistema de educación superior. Sin embargo, a medida que fui leyendo pude constatar que estaba en un error ya que muchas de las cuestiones tratadas siguen siendo, para bien o para mal, una realidad nuestra. Ahora bien, lo anterior no quiere decir que no haya habido algunos avances o cambios en la materia propuesta con el paso de los años; pero, es precisamente el tiempo lo que nos permite analizar los detalles del pasado desde otra óptica a aquel momento para ver hacia dónde y cómo queremos enfocar nuestros objetivos futuros.

En este punto, me gustaría recordar lo que dijo el célebre filósofo, ensayista, poeta y novelista George Santayana: “Aquellos que no recuerdan el pasado, están condenados a repetirlo". Sin lugar a dudas, Teichler en esta obra nos brinda esa oportunidad de conocer incluso muchos temas que ya se plantearon en otros tiempos y vuelven a estar encima de la mesa en nuestros días. Sirva de ejemplo la preocupación en los años setenta de muchos países europeos sobre el gran número de licenciados universitarios y los obstáculos a los que tuvieron que afrontar tales como el empleo inadecuado, inestable o desempleo. No cabe duda que actualmente este tema vuelve a estar en un primer plano e incluso en el marco político.

Ejemplo de todo ello es que se discuten temas de actual interés tales como: el futuro de la investigación universitaria en Europa, el debate diversidad vs homogeneización en la 
educación superior, el papel del inglés, el crecimiento de la internacionalización, la europeización de la educación superior o los nuevos factores que influyen en la estructura del sistema educativo tales como, por ejemplo, la globalización o las nuevas tecnologías.

Llegados a este punto debemos focalizar nuestra mirada en el autor, pues no se trata de un mero recopilatorio de una persona inexperta o que vagabundea en medio de términos e ideas que desconoce.

Antes bien, éste es el resultado del reconocido sociólogo, investigador y profesor Ulrich Teichler, quien posee una gran trayectoria y experiencia profesional de más de treinta años en el ámbito de la investigación sobre la educación superior. Más aún, fue director y profesor del Centro Internacional de Investigación de Educación Superior Kassel (Universität Kassel, 2019) por un período de aproximadamente dieciséis años y con más de 500 publicaciones hechas a lo largo de su vida profesional.

En concreto, respecto a los temas que más ha tratado el autor en sus diferentes publicaciones encontramos:

“...la educación superior y el mundo laboral, los avances cuantitativoestructurales de la educación superior en una perspectiva comparativa y las dimensiones internacionales de la educación superior.” (p.17)

Por consiguiente, la gran aportación científica especializada en la educación superior que ha hecho Ulrich Teichler, premiada incluso en 1998 con el "Premio Comenius" de la UNESCO, entre otros, la acreditan como una persona capaz y entendida en la materia.

Dicho lo anterior, y poniendo nuestra atención en la estructura básica de la obra, observamos una recopilación cronológica de los diferentes artículos que el autor ha ido publicando a lo largo de los años. Para ello, Teichler ha ido desarrollando cada uno de los puntos que expone atendiendo a autores, datos, informes, perspectivas y opiniones tanto actuales como relevantes de cada momento. De esta forma, y como consecuencia de ello, el lector va adquiriendo una comprensión progresiva y actualizada del tema $\underline{\text { central del libro, y dilucidar personalmente cuál es y ha sido la tendencia de la }}$ educación superior en Europa.

En otro orden de cosas, alrededor del tema central de la obra, encontramos un total de cinco puntos que el propio autor discierne claramente en este ejemplar y una que yo 
además considero interesante reconocerla de forma diferenciada. En relación con lo anterior, se debe agregar que podemos apreciar el desarrollo de estos puntos en seis secciones diferenciadas y ordenadas_tal y como expondré a continuación:

En la primera parte del libro, el autor tiene claro que para delimitar el concepto de "sistema educación superior" es determinante el estudio comparado con otros países y no tener como única referencia un país determinado. Por ello, analiza entre los diferentes países europeos los diferentes métodos de acceso a la educación superior, años de estudio, planes docentes, sistemas de evaluación llevados a cabo durante la "licenciatura", "másteres" o estudios de postgrado, la vinculación entre los programas reglados y no reglados junto con el grado de permeabilidad entre ellas. En pocas palabras, creo que este apartado es esencial a modo introductorio para poder comprender, a mi parecer, el principal problema existentes hasta finales de los años noventa en el sistema de educación superior. Tal y como concluye el autor:

"En general, no se observa una tendencia global hacia la convergencia europea de los aspectos estructurales y organizativos de los estudios y su contexto" (p.95)

Seguidamente, en una segunda sección, se pormenoriza en el concepto de "educación superior" con la que el autor está más de acuerdo y no otras referencias como "educación universitaria o "educación terciaria" más utilizadas en tiempos atrás. También en esta parte, se pone encima de la mesa cómo ha ido cambiando la concepción de esta etapa educativa en los diferentes países y épocas teniendo en cuenta el grado de importancia que se le ha dado en cada momento incluso en el mapa político. Y, en este último punto, considero que, independientemente al momento histórico concreto, darle la consideración debida a la educación es vital para el desarrollo social, científico, tecnológico y, consecuentemente, económico.

A continuación, la siguiente sección tiene mucha relación con la anterior, puesto que Teichler se adentra en apreciar si verdaderamente existen notas diferenciadoras entre la educación superior universitaria y no universitaria. A la vez, en esta parte se menciona sobre el fenómeno de la coexistencia de ambas instituciones y la duda que por cierto tiempo se mantuvo sobre la persistencia de las instituciones no universitarias diferenciadas frente a las universitarias. Este posicionamiento cogió cierta fuerza cuando en 1992 se constató la conversión de las politécnicas británicas en centros universitarios. En ese momento, no fueron pocos los que pensaron que esa "deriva 
académica" iba a ser el transcurso natural que también iban a producirse en otros países europeos. Sin embargo, hasta nuestros días, hemos podido evidenciar que ese pronóstico no ha llegado a cumplirse. De todo esto, nos habla el autor con más detenimiento en su obra sobre los motivos y recomendaciones futuras en esta materia.

En cuarto lugar, Teichler se involucra a estudiar la expansión del sistema educativo. En este planteamiento, podríamos ver la parte más crítica pero cauta del autor, ya que considera que es importante no asociar la expansión de la educación superior únicamente al incremento del número de alumnos matriculados de una franja de edad determinada sino a tener en cuenta otros condicionantes que conlleven a tener una mayor perspectiva a fin de poder hablar de "expansión" o "magnitud" de la educación superior apropiadamente.

En quinto lugar, se trata sobre la parte estructural de la educación superior en los diferentes países europeos. En consecuencia, aquí se trata el debate que por mucho tiempo ha existido en los países europeos entre la diversidad o la estandarización de la educación superior. Esta sección viene a ser la continuación de la primera sección del libro puesto que se centra en esa segunda etapa donde la tendencia empieza a girar ya en torno a la necesidad de crear un Espacio Europeo de Educación Superior por la cual se firma la Declaración de Bolonia en 1999. Pues bien, uno de los capítulos más destacados de esta sección por su interés actual y que ha tenido mucha expectación estos últimos años, es aquel donde el autor examina el proceso de Bolonia en el año 2006. Al respecto, considero interesante observar los pros y los contras que se preveían en ese momento por los expertos antes que se produjese la implantación total del "Plan Bolonia” en el año 2010 y compararlo con los resultados obtenidos nueve años después.

Y, finalmente, en la última parte de la obra, encontramos la sección donde el autor expone las dificultades y nuevas realidades existentes en el ámbito de la investigación universitaria en Europa. Sobre este aspecto, considero fundamental ser conscientes de la realidad que se vive en este sector y darle el reconocimiento merecido por su implicación directa en la mejora o no de la calidad del sistema educativo.

En definitiva, considero que "Sistemas comparados de educación superior en Europa" es un ejemplar muy útil dentro del campo de la investigación sobre esta temática por su rigor científico y análisis de diferentes elementos que después son sintetizados en una conclusión clara al final de cada capítulo. Ahora bien, esto no quiere decir que la obra no pueda ser comprensible para un público más general ya que Teichler utiliza un 
lenguaje claro, ameno, sencillo y directo sobre temas que también son o deben ser de interés general.

Indiscutiblemente, ésta es una obra que permite al lector pensar y entender mejor el tema que se trata extrayendo incluso sus propias valoraciones gracias a la gran aportación del autor mediante ejemplos, datos estadísticos, informes, estudios y obras tanto propias como de otros autores relevantes en la materia. Por todo ello, considero posible concluir diciendo que Ulrich Teichler ha cumplido con la finalidad que se propuso en este libro cuando lo definió como: “... una colección de 'artículos para la reflexión"” (p.22).

Ana María Enríquez Rodríguez

Facultat de Dret

Universitat de Barcelona (UB)

E-mail: aenriqro7.alumnes@ub.edu 